\title{
Proposed organization of family cancer clinics in Indonesia
}

\author{
Kunta Setiaji* \\ Division of Surgical Oncology, Department of Surgery Universitas Gadjah Mada
}

DOI: http://dx.doi.org/10.19106/JMedScieSup0048042016016

\section{ABSTRACT}

Around $10-15 \%$ of breast cancers are associated hereditary and/or familial predisposition. Familial breast cancer is defined as the case that occurs in two or more first degree relatives within a nuclear pedigree (first or second degree relatives). Hereditary and familial cancer display different characteristics in pathological features, clinical course, response to treatment, and outcome. Therefore, specific consultation and treatment need to be addressed to patients with hereditary or familial predisposition, e.g. the need for rigorous surveillance and preventive treatment including preventive surgery. Cancer clinical genetic service is not yet formally available in daily clinical practice in Indonesia. Surgeons usually become the first medical specialist to see cancer patients with familial predisposition, thus they have to integrate clinical cancer genetics service under Family Cancer Clinic (FCC). Clinical genetics service within FCC consists of several step-wise tasks, including assessment of personal and family history of cancer, personalized cancer risk assessment, review of medical and family history, individual cancer screening and surveillance recommendations, genetic testing if necessary, discussion of benefits and limitations of genetic test, cancer risk reduction options, preventive strategies, and opportunity to participate in research as well as clinical trial. Nation-wide network for FCC is important to facilitate knowledge and skill sharing in order to perform cancer genetics service. Ability to perform genetic test and interpretation in Indonesia is also required.

Keywords: familial cancer, hereditary cancer, genetic counseling, family cancer clinics 